Cochrane Database of Systematic Reviews

\title{
Antiplatelet therapy for preventing stroke and other vascular events after carotid endarterectomy (Review)
}

Engelter S, Lyrer P

Engelter S, Lyrer P.

Antiplatelet therapy for preventing stroke and other vascular events after carotid endarterectomy.

Cochrane Database of Systematic Reviews 2003, Issue 3. Art. No.: CD001458.

DOI: 10.1002/14651858.CD001458.

www.cochranelibrary.com 
TABLE OF CONTENTS

HEADER

ABSTRACT

PLAIN LANGUAGE SUMMARY

BACKGROUND

OBJECTIVES

METHODS

RESULTS

DISCUSSION

AUTHORS' CONCLUSIONS

ACKNOWLEDGEMENTS

REFERENCES

CHARACTERISTICS OF STUDIES

DATA AND ANALYSES

Analysis 1.1. Comparison 1 Antiplatelets versus control, Outcome 1 Death (all causes).

Analysis 1.2. Comparison 1 Antiplatelets versus control, Outcome 2 Stroke (any stroke during the follow-up period).

Analysis 1.3. Comparison 1 Antiplatelets versus control, Outcome 3 Vascular death.

Analysis 1.4. Comparison 1 Antiplatelets versus control, Outcome 4 Stroke or vascular death.

Analysis 1.5. Comparison 1 Antiplatelets versus control, Outcome 5 Serious vascular events during follow-up period.

Analysis 1.6. Comparison 1 Antiplatelets versus control, Outcome 6 Death or dependency at the end of follow up.

Analysis 1.7. Comparison 1 Antiplatelets versus control, Outcome 7 Myocardial infarction (all).

Analysis 1.8. Comparison 1 Antiplatelets versus control, Outcome 8 Non-fatal myocardial infarction.

Analysis 1.9. Comparison 1 Antiplatelets versus control, Outcome 9 Ischaemic stroke during follow-up period.

Analysis 1.10. Comparison 1 Antiplatelets versus control, Outcome 10 Intracranial haemorrhage.

Analysis 1.11. Comparison 1 Antiplatelets versus control, Outcome 11 Major extracranial haemorrhage.

Analysis 1.12. Comparison 1 Antiplatelets versus control, Outcome 12 Local haemorrhage requiring surgery.

Analysis 1.13. Comparison 1 Antiplatelets versus control, Outcome 13 Recurrent stenosis.

Analysis 1.15. Comparison 1 Antiplatelets versus control, Outcome 15 TIA or amaurosis fugax.

WHAT'S NEW

CONTRIBUTIONS OF AUTHORS

DECLARATIONS OF INTEREST

SOURCES OF SUPPORT

DIFFERENCES BETWEEN PROTOCOL AND REVIEW

INDEX TERMS 
[Intervention Review]

\section{Antiplatelet therapy for preventing stroke and other vascular events after carotid endarterectomy}

Stefan Engelter ${ }^{1}$, Philippe Lyrer ${ }^{1}$

1Department of Neurology, University Hospital Basel, Basel, Switzerland

Contact address: Philippe Lyrer, Department of Neurology, University Hospital Basel, Petersgraben 4, Basel, 4031, Switzerland. plyrer@uhbs.ch.

Editorial group: Cochrane Stroke Group

Publication status and date: Edited (no change to conclusions), published in Issue 1, 2010.

Citation: Engelter S, Lyrer P. Antiplatelet therapy for preventing stroke and other vascular events after carotid endarterectomy. Cochrane Database of Systematic Reviews 2003, Issue 3. Art. No.: CD001458. DOI: 10.1002/14651858.CD001458.

Copyright @ 2010 The Cochrane Collaboration. Published by John Wiley \& Sons, Ltd.

\section{A B S T R A C T}

\section{Background}

Antiplatelet drugs are effective and safe in a wide variety of patients at high risk of vascular ischaemic events. Among patients undergoing vascular surgical procedures, these agents significantly reduce the risk of graft or native vessel occlusion. In this context we wished to examine their effects in patients after carotid endarterectomy (CEA).

\section{Objectives}

To evaluate whether antiplatelet agents are safe and beneficial after endarterectomy of the internal carotid artery.

\section{Search methods}

We searched the Cochrane Stroke Group Trials Register (last searched 1 October 2002). In addition we performed comprehensive searches of the Cochrane Controlled Trials Register (The Cochrane Library Issue 3, 2002), MEDLINE (January 1966 to September 2002) and EMBASE (January 1980 to September 2002), and checked all relevant papers for additional eligible studies.

\section{Selection criteria}

We selected randomised, controlled, unconfounded trials comparing antiplatelet agents with control after carotid endarterectomy in symptomatic or asymptomatic carotid stenosis of different degrees. Treatment duration had to be at least 30 days after CEA. Follow up should be at least three months.

\section{Data collection and analysis}

Two review authors selected trials for inclusion, assessed trial quality, and extracted data independently from each other. From each trial we extracted the number of patients originally allocated to each treatment group, and the number of patients who met the criteria for each outcome (intention-to-treat analysis). We calculated a weighted estimate of the odds for each outcome event across studies using the Peto odds ratio method.

\section{Main results}

Six trials involving 907 patients were identified. For 'death (all causes)' the Peto odds ratio of 0.77 with a $95 \%$ confidence interval (Cl) of 0.48 to 1.24 did not show a statistically significant difference between both treatment groups. For 'stroke (any)' the Peto odds ratio of 0.58 ( $95 \%$ $\mathrm{Cl}: 0.34$ to 0.98$)$ indicated a statistically significant benefit in favour of antiplatelet drugs $(\mathrm{P}=0.04)$. For 'vascular death', 'stroke or vascular death', 'serious vascular events', 'death or dependency', 'myocardial infarction', 'major extracranial haemorrhage', 'local haemorrhage requiring surgery', 'restenosis', 'TIA or amaurosis fugax', neither any benefit nor any hazard of antiplatelet drugs could be shown. For the 
outcome events 'intracranial haemorrhage', 'ischaemic stroke' and 'occurrence or progression of contralateral stenosis', data were either too sparse for meaningful analyses, or not available at all.

\section{Authors' conclusions}

Our results may indicate that antiplatelet drugs did not significantly change the odds of death but reduce the outcome 'stroke of any cause' in patients undergoing carotid endarterectomy. However, it can not be excluded that the beneficial effect in reducing stroke is due to chance. There is a suggestion that antiplatelets may increase the odds of haemorrhage, but there are currently too few data to quantify this effect.

\section{PLAIN LANGUAGE SUMMARY}

\section{Antiplatelet therapy for preventing stroke and other vascular events after carotid endarterectomy}

Patients with narrowing of one of the major blood vessels to the brain, the internal carotid artery, are at risk of stroke. The surgical operation to remove the narrowing (carotid endarterectomy) can reduce the long-term risk of stroke. Drugs such as aspirin which prevent blood platelets forming clots (antiplatelet drugs) can also reduce the risk of stroke, but can sometimes cause serious bleeding. This review showed that antiplatelet drugs can also reduce the risk of stroke in patients undergoing carotid endarterectomy. There was limited information on bleeding risk. The review's conclusions supported the routine use of antiplatelet drugs such as aspirin in patients having carotid endarterectomy. 


\section{B A C K G R O U N D}

Carotid artery disease is supposed to be responsible for $20 \%$ to $30 \%$ of the new strokes annually occurring in the United States (Timsit 1992). To prevent stroke due to internal carotid stenosis, carotid endarterectomy (CEA) is of proven benefit for symptomatic patients, whereas the evidence for asymptomatic patients is less strong. A systematic Cochrane review (Cina 2002) based on the data from ECST (ECST 1998) and NASCET (NASCET 1991; NASCET 1998) showed that for patients with high grade symptomatic carotid stenosis the number needed to be operated on to prevent one disabling stroke or death over two to six years was $15(95 \%$ confidence interval ( $\mathrm{Cl}) 10$ to 31 ). If the symptomatic stenosis is of moderate degree, the number needed to treat increased to 21 (95\% Cl 11 to 125) (Cina 2002). A systematic review on patients with asymptomatic carotid stenosis revealed "a barely significant, and extremely small [beneficial] effect in terms of absolute risk reduction" (Chambers 2002).

Antiplatelet agents (mainly acetylsalicylic acid) are beneficial to most stroke patients (IST 1997; ATT 2002). The Antithrombotic Trialists' Collaboration provided good evidence that, for patients with various manifestations of occlusive atherosclerotic disease who are at high risk of ischaemic events, antiplatelet agents reduce the risk of serious vascular events (ATT 2002; ATT 1994a), occlusion of vascular grafts and native arteries (ATT 1994b), and deep vein thrombosis or pulmonary embolism (ATT 1994c).

The risk of major haemorrhagic events in these patients was small (ATT 2002; ATT 1994a; ATT 1994b; ATT 1994c). However, in patients undergoing carotid surgery, antiplatelet therapy (at least theoretically) might cause an excess in major haemorrhagic complications and might therefore be potentially harmful.

In this situation we wished to explore the effects of antiplatelet agents for CEA patients.

\section{OB JECTIVES}

The objective of this review was to evaluate whether antiplatelet agents are safe and beneficial after endarterectomy of the internal carotid artery. We wished to determine whether antiplatelet agents after CEA:

(1) prevent stroke;

(2) reduce death and dependency;

(3) reduce the risk of vascular events other than stroke (myocardial infarction, vascular death, transient ischaemic attack (TIA), or amaurosis fugax);

(4) reduce the risk of recurrent stenosis of the operated internal carotid artery and may prevent progression of stenosis in the contralateral internal carotid artery; and

(5) increase the risk of serious haemorrhagic events (intracranial haemorrhage, major extracranial haemorrhage).

\section{METHODS}

\section{Criteria for considering studies for this review}

\section{Types of studies}

We searched for all randomised, unconfounded controlled trials (RCTs) comparing antiplatelet agents with placebo or control after CEA. We included studies of patients who underwent CEA of symptomatic and asymptomatic carotid stenosis of different degrees. Case series and non-randomised trials were not considered.

\section{Types of participants}

Studies reporting on patients of either gender who underwent CEA for stenosis of the internal carotid artery were included.

\section{Types of interventions}

Included were studies with patients having symptomatic and asymptomatic carotid stenosis who underwent different techniques of CEA including patch, direct suture, shunt from common carotid artery to internal carotid artery. Trials in patients who underwent angioplasty, stent implantation, or bypass surgery were not considered.

Trials included one patient group receiving treatment with antiplatelet agents which was compared to another group with no treatment or placebo after CEA. The following antiplatelet agents alone or in combination were considered: acetylsalicylic acid (aspirin), lysin-acetylsalicylic acid, dipyridamole, ticlopidine, sulphinpyrazone, clopidogrel, and indobufen.

Randomly allocated antiplatelet medication had to be started within three months before CEA but not later than three months after surgery. Treatment duration had to be at least 30 days after CEA. Trials comparing post-carotid endarterectomy 'best medical therapy' versus 'best medical therapy plus antiplatelet therapy' were to be included. Follow up had to be at least three months, but longer follow up was also included. Trials comparing antiplatelet agents with anticoagulants after CEA were not considered.

\section{Types of outcome measures}

We extracted from each trial the number of patients originally allocated to each treatment group (intention-to-treat analysis). We then extracted the number of patients within each trial who met the criteria for outcomes as follows.

\section{Primary outcomes}

(1) Death (all causes).

(2) Stroke (any stroke during follow-up period). This outcome includes ischaemic strokes (definition see 9), intracranial haemorrhage (definition see 10), or stroke of unknown aetiology.

\section{Secondary outcomes}

(3) Vascular death, which we defined as death caused by:

(a) stroke or a complication of stroke (e.g. brain herniation, status epilepticus, etc.)

(b) coronary artery disease or a complication of it (e.g. myocardial infarction, congestive heart failure, arrhythmia)

(c) sudden death

(d) pulmonary embolism

(e) peripheral vascular disease

(f) haemorrhage (intracranial or extracranial) or

(g) other vascular causes (e.g. rupture of aneurysm, dissection, etc.) including 'vascular death' mentioned without specification in the publications.

(4) Stroke or vascular death. This composite outcome includes all patients who qualified for either outcome event 2 , or 3 , or both. 
(5) Serious vascular events during follow-up period. This composite outcome includes all patients who qualified for either outcome event 'vascular death' (definition see 3), or 'any stroke' (definition see 2), or 'non-fatal myocardial infarction' (definition see 8 ).

(6) Death or dependency at the end of follow up. This composite outcome includes all patients who qualified either for death (definition see 1) or dependency (handicap) which is defined according to the modified Rankin Scale (m-RS): independency ( 0 to 2 ) is distinguished from dependency ( 3 to 5 ). When $m-R S$ values are not available, independency is defined as recovery (i.e. patients are able to look after own affairs without assistance) or regain of work and dependency as 'partial improvement', 'no improvement', 'no recovery', 'inability to walk without assistance', or 'requiring some help for bodily activities of daily living'.

(7) Myocardial infarction (MI) (all). All patients with fatal or nonfatal MI. Patients who died of occlusive coronary artery disease as reported by autopsy, are classified as 'fatal myocardial infarction'.

(8) Non-fatal myocardial infarction. All patients who experienced non-fatal Mls according to the definition of the study investigators. Patients with probable and definite non-fatal MIs were included.

(9) Ischaemic stroke during follow-up period. Ischaemic stroke is defined as any neurological deficit due to cerebral ischaemia lasting longer than 24 hours, and showing no evidence of any other underlying pathology (e.g. haemorrhage, tumour).

(10) Intracranial haemorrhage. Intracranial haemorrhage includes any subarachnoid haemorrhage, subdural haemorrhage, epidural haematoma, or parenchymatous intracerebral haemorrhage, as confirmed by neuroradiological investigations or by autopsy. Haemorrhagic transformation of an ischaemic infarction was not considered as intracranial haemorrhage.

(11) Major extracranial haemorrhage. The definition of a major extracranial haemorrhage was taken from the original publication. If no definition was given, we defined major as a fatal bleeding, or one requiring surgery, transfusion or (prolonged) hospitalisation. If haemorrhage was declared 'serious' or 'severe' in the publication, it was considered as a major haemorrhage for the purpose of this review.

(12) Local haemorrhage requiring surgery. All patients with local haematoma requiring surgical exploration, haematoma evacuation, or application of a suture, a patch, or a bypass met the criteria for this outcome event.

(13) Recurrent stenosis. Recurrent stenosis is defined as follows (de Bray 1995): in angiography: stenosis greater than $50 \%$ in diameter according to NASCET criteria or greater than $75 \%$ using ECST criteria. In Doppler and duplex sonography: stenosis of more than $50 \%$ diameter reduction, i.e. at the narrowest point of the stenosis a maximum Doppler shift of at least $4.0 \mathrm{kHz}$ (Doppler sonography), or a peak flow velocity of at least $120 \mathrm{~cm} / \mathrm{s}$ and a systolic carotid ratio (between internal and common carotid artery) of at least 1.5 (duplex sonography) have to be measured.

(14) Occurrence or progression of contralateral stenosis. Occurrence of stenosis of the contralateral internal carotid artery as defined in 9, which was recorded for the first time after ipsilateral CEA, i.e. which was not present before. Progression of contralateral stenosis was defined in case of any increase of the degree of contralateral stenosis of at least 10\% (NASCET criteria) angiographically, an increase in maximal Doppler shift by at least 1 $\mathrm{kHz}$ compared to preoperative doppler sonography, or an increase in diastolic flow velocity of at least $50 \mathrm{~cm} / \mathrm{s}$.

(15) Transient ischaemic attack (TIA) or amaurosis fugax (AF).

For composite outcome events (i.e. outcome parameter 4, 5, 6, and 15), patients were included only once. If one patient experienced more than one non-fatal event, only the first one was recorded.

\section{Search methods for identification of studies}

See: 'Specialized register' section in Cochrane Stroke Group

Relevant trials were identified in the Specialised Register, which was last searched for this review by the Review Group Co-ordinator on 1 October 2002. We performed comprehensive searches of the Cochrane Controlled Trials Register (The Cochrane Library Issue 3, 2002), MEDLINE (January 1966 to September 2002) and EMBASE (January 1980 to September 2002), using the following search strategies and checked all relevant papers for additional eligible studies.

\section{MEDLINE (Ovid) and Cochrane Controlled Trials Register}

1 endarterectomy, carotid/

2 exp carotid artery diseases/su (surgery)

3 exp carotid arteries/su

4 exp carotid arteries/ or exp carotid artery diseases/

5 endarterectomy/ or vascular surgical procedures/

64 and 5

7 (carotid adj5 (endarterectom $\$$ or surgery)).tw.

81 or 2 or 3 or 6 or 7

9 exp Platelet aggregation inhibitors/

10 (antiplatelet $\$$ or anti-platelet $\$$ or antiaggreg $\$$ or anti-aggreg $\$$ or (platelet\$ adj5 inhibit\$) or (thrombocyt\$ adj5 inhibit\$)).tw.

11 (alprostadil\$ or aspirin $\$$ or dipyridamol\$ or disintegrin\$ or epoprostenol\$ or iloprost\$ or ketanserin\$ or ketorolac or tromethamine\$ or milrinone or mopidamol\$ or pentoxifyllin $\$$ or procainamide\$ or sulfinpyrazone or sulphinpyrazone or indobufen or ticlopidine or thiophen\$ or trapidil\$).tw.

12 (acetyl salicylic acid\$ or acetyl?salicylic acid or clopidogrel\$ or picotamide\$ or ligustrazine\$ or levamisol\$ or suloctidil\$ or ozagrel $\$$ or oky046 or oky-046 or defibrotide\$ or cilostazol or satigrel or sarpolgrelate or kbt3022 or kbt-3022 or isbogrel or cv4151 or cv-4151 or triflusal).tw.

13 (Dispril or Albyl\$ or Ticlid\$ or Persantin\$ or Plavix).tw.

14 exp Platelet glycoprotein gpiib-iiia complex/ai,de

15 (((glycoprotein iib\$ or gp iib\$) adj5 (antagonist\$ or inhibitor\$)) or GR144053 or GR-144053 or abciximab\$ or tirofiban\$ or eftifibatid \$).tw.

16 (ReoPro or Integrilin\$ or Aggrastat).tw.

17 exp Platelet activation/de (drug effects)

18 exp Blood platelets/de

199 or 10 or 11 or 12 or 13 or 14 or 15 or 16 or 17 or 18

208 and 19

21 limit 20 to human

\section{EMBASE (Ovid)}

1. carotid endarterectomy/

2 carotid artery surgery/ 
3 exp carotid artery disease/su (surgery)

4 exp carotid artery/

5 exp carotid artery disease/

64 and 5

7 artery surgery/ or vascular surgery/ or surgery/

86 and 7

9 (carotid adj5 (endarterectom\$ or surgery)).tw.

101 or 2 or 3 or 8 or 9

11 exp Antithrombocytic agent/

12 (antiplatelet $\$$ or anti-platelet $\$$ or antiaggreg $\$$ or anti-aggreg $\$$ or

(platelet\$ adj5 inhibit\$) or (thrombocyt\$ adj5 inhibit\$)).tw.

13 (Acetylsalicylic Acid\$ or Argatroban or Beraprost or Cicaprost or Cilostazol or Clopidogrel or Dipyridamole or lloprost or Indobufen or Lepirudin or Pentosan Polysulfate or Pentoxifylline or Piracetam or Prostacyclin or Sulfinpyrazone or Sulphinpyrazone or Ticlopidine or Trifusal or Abciximab or Disintegrin or Echistatin or Eptifibatide or Lamifiban or Orbofiban or Roxifiban or Sibrafiban or Tirofiban or Xemilofiban).tw.

14 (alprostadil\$ or aspirin\$ or acetyl salicylic acid\$ or acetyl? salicylic acid or eprostenol\$ or epoprostenol\$ or ketanserin $\$$ or ketorolac tromethamine\$ or milrinone\$ or mopidamol\$ or procainamide\$ or thiophen $\$$ or trapidil\$ or picotamide\$ or ligustrazine\$ or levamisol\$ or suloctidil\$ or ozagrel\$ or oky046 or oky-046 or defibrotide\$ or cilostazol or satigrel or sarpolgrelate or kbt3022 or kbt-3022 or isbogrel or cv4151 or cv-4151 or ((glycoprotein iib\$ or gp iib\$) adj5 (antagonist\$ or inhibitor\$)) or GR144053 or GR-144053 or trifusal).tw

15 (Dispril or Albyl\$ or Ticlid\$ or Persantin\$ or Plavix or ReoPro or Integrilin\$ or Aggrastat).tw.

16 Fibrinogen receptor/dt (drug therapy)

17 Thrombocyte/

1811 or 12 or 13 or 14 or 15 or 16 or 17

1910 and 18

20 limit 19 to human

Furthermore, the reference lists from published papers as well as the data ascertained by the Antithrombotic Trialists' Collaboration (ATT 2002), section 'carotid disease' were screened for further studies.

\section{Data collection and analysis}

Studies were selected by two independent authors (SE, PL). Data items on the number of outcome events were extracted by two reviewers (SE, PL) onto a data extraction form independent of each other. In cases of disagreement, a consensus was reached by discussion.

Because none of the included RCTs (see Description of studies) provided complete information concerning all outcomes in publications, data from the carotid disease group of the collaborative meta-analysis on antiplatelet therapy for prevention of serious vascular events by the Antithrombotic Trialists' Collaboration (ATT 2002) were used. Furthermore, efforts were made to contact principle investigators. As a result, additional data were obtained from one study (Boysen 1988). Thus, the present version of this review is based on published data in five RCTs and published data plus personal communication in one RCT.

\section{Statistical methods}

Data on the number of patients in each group and with each outcome event, irrespective of compliance, and whether or not the patient was subsequently deemed ineligible or was excluded from treatment or follow-up because of any other reason were sought in order to do an intention-to-treat analysis. Additional data were sought on the characteristics of patients included (i.e. age, sex, symptomatic versus asymptomatic stenosis), on the antiplatelet regimen (i.e. agent, daily dose, duration), on the surgical technique (e.g. shunt, patch), on the type of anaesthesia (i.e. general, local), and the duration of the follow-up period.

We calculated a weighted estimate of the odds for each outcome event across studies using the Peto odds ratio method. For cases of marked imbalance of the numbers between treatment and control groups, we decided to use Mantel-Haenszel odds ratios. However, no such imbalance occurred in the trials. Chi-square test was used to test for heterogeneity across studies.

\section{RES U L T S}

\section{Description of studies}

We have identified a total of nine RCTs so far. One trial was excluded because results were neither published nor data available by personal contact with the principal investigator (McCollum 1993). Two other trials were excluded because treatment duration was too short (Findlay 1985; Pedrini 1988) and follow-up time was not specified (Findlay 1985), respectively. Six RCTs including 907 patients met our inclusion criteria.

In two of the six trials included, only those patients were randomised who had undergone surgery of a symptomatic stenosis (AITIA-S 1978; Pratesi 1991). Both trials included only TIA patients. In three additional trials, patients with symptomatic as well as asymptomatic stenosis were included. The percentage of symptomatic stenosis ranged from 62\% (Kretschmer 1990) to $93 \%$ (one third with stroke) (Lindblad 1993) up to 97\% (Boysen 1988). The ratio of symptomatic and asymptomatic stenoses was equally distributed among treatment groups in these trials. In another trial, the exact number of patients with symptomatic versus those with asymptomatic stenosis remained unclear (Harker 1992). In total, stenoses were symptomatic in 693 patients, asymptomatic in 51 patients, and of unknown type in 163 patients, respectively (for details see Characteristics of included studies).

Neither details about the degree of stenosis prior to randomisation nor information about the distribution of degrees of stenoses among both treatment groups were available for most trials (AITIAS 1978; Boysen 1988; Harker 1992; Pratesi 1991; Kretschmer 1990). In one trial, preoperative duplex sonography showed a median degree of stenosis of $80 \%$ in both treatment groups (with a range of $25 \%$ to $90 \%$ ) in both groups (Lindblad 1993). Another study mentioned, 'in most patients (75\%) ..., stenosis was > 50\%' (AITIA$S$ 1978). Further baseline characteristics such as age, gender, and the presence of vascular risk factors (i.e. hypertension, diabetes, smoking) were equally distributed among both treatment groups within all trials.

In hardly any of the trials were the CEA techniques and the applied anaesthesia types described in detail. In one trial, CEAs were performed under general anaesthesia in $88 \%(205 / 232)$ of the patients and shunts were used in $41 \%$ of the patients, equally balanced between both treatment groups (Lindblad 1993). In another trial, CEAs with polytetrafluoroethylene or autologous vein grafts followed by angioplasty were performed (Pratesi 1991). 
"Thrombendarterectomy of the carotid bifurcation without using an intraluminal shunt ..... and the arteriotomy was closed by direct suture" was mentioned in another trial (Kretschmer 1990). A "standard CEA procedure" was mentioned by others (Harker 1992), whereas information about surgical techniques and type of anaesthesia was not available in two trials (AITIA-S 1978, Boysen 1988).

Five of the six trials included used acetylsalicylic acid (ASA) as the antiplatelet agent. Four trials administered ASA as antiplatelet monotherapy in a daily dosage of $75 \mathrm{mg}$ (Lindblad 1993), 50 to $100 \mathrm{mg}$ (Boysen 1988), $1000 \mathrm{mg}$ (Kretschmer 1990), and 1300 mg (AITIA-S 1978), respectively. Combined ASA (990 mg per day) and dipyridamole (225 mg per day) were used in the fifth trial (Harker 1992). In one trial, indobufen $400 \mathrm{mg}$ per day was administered (Pratesi 1991). In five trials, the control group received placebo, in one trial the control group received 'no-antiaggregating medication' (Kretschmer 1990).

The onset of study medication (i.e. antiplatelets or placebo) ranged from two days prior to CEA until three months after CEA. In detail, study medication begun 'the evening before' (Lindblad 1993), 12 hours (Harker 1992) and two days (Pratesi 1991; Kretschmer 1990) prior to CEA and five days (AITIA-S 1978) and up to three months after CEA (Boysen 1988), respectively. Treatment duration ranged from six months (Lindblad 1993; Pratesi 1991), to 12 months (Harker 1992), 24 months (AITIA-S 1978), up to 27 months (average 25 months) (Boysen 1988), and up to six years (average 54 months) (Kretschmer 1990), respectively. The duration of follow up paralleled the mentioned treatment period within each trial.

For the primary outcomes (i.e. death (all causes) and stroke (any)), the analyses were based on data of all the six trials included. For the secondary outcome event 'occurrence or progression of contralateral stenosis', only insufficient data were available. Analyses of the other secondary outcomes were based on a various number of RCTs. Analyses of 'death or dependency', 'ischaemic stroke' or 'intracranial haemorrhage' were based on one RCT. Analyses concerning 'myocardial infarction' (fatal or nonfatal)', 'non-fatal myocardial infarction', 'recurrent stenosis', 'TIA or amaurosis fugax' or 'local haemorrhage requiring surgery' were based on three RCTs. Analyses about 'vascular death', 'stroke or vascular death', 'serious vascular events', or 'major extracranial haemorrhage' were based on five RCTs.

\section{Risk of bias in included studies}

See also Characteristics of included studies

Quality assessment of trials: details were obtained regarding blinding, randomisation (generation and concealment of randomisation sequence), number of randomised patients as well as the number of drop outs, withdrawals, cross-over treatment and those lost to follow up. In case of missing information we tried to contact the corresponding authors.

In order to rate the methodological quality of the trials, the assessment scale of Jadad et al (Jadad 1996) was applied. Assessment was performed by two independent reviewers (SE, PL). In case of discordance, consensus was reached by discussion. Up to five points were given for the quality of RCTs: the higher the score, the better the methodological RCT quality.
Among the six trials included, two reached five points (Harker 1992; Boysen 1988), one reached four points (Pratesi 1991), another two reached three points (Lindblad 1993; AITIA-S 1978), whereas one trial had two points (Kretschmer 1990). Please see 'Notes' in Characteristics of included studies for details on randomisation, drop outs and losses to follow up, which explain the different scores.

\section{Effects of interventions}

See also lists of comparisons.

\section{Primary outcome events}

\section{Comparison 1.1: Death (all causes)}

For the outcome 'death of all causes' at the end of the follow-up period, data from all six trials included could be obtained ( $N=907$ patients). Three of the six trials had less fatal outcome events in the antiplatelet group than in the control group (Kretschmer 1990; Harker 1992; Lindblad 1993), one trial had no 'deaths of all causes' in either group (Pratesi 1991), while in two trials more deaths among patients treated with antiplatelets occurred (AITIA-S 1978; Boysen 1988). Within trials the differences between antiplatelet and control group were not statistically significant. Across all trials, the Peto odds ratio was 0.77 in favour of antiplatelet agents, however, a $95 \%$ confidence interval $(\mathrm{Cl})$ of 0.48 to 1.24 indicated that statistical significance was missing.

\section{Comparison 1.2: Stroke (any stroke during follow-up period)}

All six trials reported on strokes during follow up ( $N=907$ patients). In one trial, strokes occurred in neither treatment group (Pratesi 1991). In the remaining five trials, strokes as outcome events were less frequent in the antiplatelets group than in the placebo group (AITIA-S 1978; Boysen 1988; Kretschmer 1990; Harker 1992; Lindblad 1993). These findings reached statistical significance only within one trial (AITIA-S 1978). Across studies, the Peto odds ratio of 0.58 with a $95 \% \mathrm{Cl}$ of 0.34 to 0.98 indicated a statistically significant beneficial effect in favour of antiplatelet agents in reducing stroke of any type $(P=0.04)$. There was no significant heterogeneity among trials $(P=0.68)$.

\section{Secondary outcome events}

\section{Comparison 1.3: Vascular death}

Analysis in respect to vascular death is based on five trials ( $N=675$ patients). The Peto odds ratio of 0.96 with a $95 \% \mathrm{Cl}$ of 0.54 to 1.71 indicated neither any benefit nor any hazard of antiplatelet drugs concerning vascular death.

\section{Comparison 1.4: Stroke or vascular death}

Five trials ( $\mathrm{N}=675$ patients) mentioned data enabling the analysis of this composite endpoint at the end of the follow-up period. No significant difference was observed between treatment and control group regarding stroke or vascular death indicated by a Peto odds ratio of 0.81 with a $95 \% \mathrm{Cl}$ of 0.51 to 1.30 .

\section{Comparison 1.5: Serious vascular events during follow-up period}

Five trials ( $\mathrm{N}=675$ patients) mentioned data enabling the analysis of this composite endpoint at the end of the follow-up period. Three of these five studies (Harker 1992; Pratesi 1991, Kretschmer 1990) did not explicitly mention whether MI occurred in study patients. The data for serious vascular events were obtained from 
the Antithrombotic Trialists' Collaboration (ATT 2002) and were identical to those of the event 'vascular death or stroke' in these three studies. In one trial serious vascular events occurred in neither treatment group (Pratesi 1991). In two trials, these events occurred roughly equally often in both groups (AITIA-S 1978; Boysen 1988), while two trials had serious vascular events less often among patients treated with antiplatelets than among patients in the control group (Harker 1992; Kretschmer 1990). However, in only one of the latter two trials the difference was statistically significant (Kretschmer 1990). For all five trials a Peto odds ratio of 0.78 with a $95 \% \mathrm{Cl}$ of 0.49 to 1.22 indicated that the difference between antiplatelet drugs and control in regard of 'serious vascular events' was not statistically significant.

\section{Comparison 1.6: Death or dependency at the end of follow up}

Only one trial did report on death and stroke related dependency (reported as stroke without complete recovery) (Lindblad 1993). In the antiplatelet group $6 / 117$ (5.1\%) patients versus $21 / 115(18.3 \%)$ patients in the control group were dead or dependent at the end of the follow-up period. A Peto odds ratio of 0.28 with a $95 \% \mathrm{Cl}$ of 0.13 to $0.62(P=0.002)$ indicated a statistically significant benefit in favour of antiplatelet therapy. However, due to the small numbers of events, a meaningful interpretation is not possible.

\section{Comparison 1.7: Myocardial infarction (all)}

Three trials $(\mathrm{N}=446)$ reported MI. No statistically significant difference between both treatment groups was shown by a Peto odds ratio of 1.42 with a wide $95 \% \mathrm{Cl}$ of 0.40 to 5.07 . There were too few events $(\mathrm{N}=10)$ to give reasonable estimates of a possible effect in respect of $\mathrm{MI}$.

\section{Comparison 1.8: Non-fatal myocardial infarction}

As a subgroup of outcome event 7 , three trials $(N=446)$ reported non-fatal MI. A Peto odds ratio of 0.48 with a wide $95 \% \mathrm{Cl}$ of 0.10 to 2.42 indicated no statistically significant difference between both treatment options. However, there were too few events $(\mathrm{N}=6)$ to give reasonable estimates of a possible effect. For fatal MI data of only two trials were available. In one trial, fatal MI occurred only in the control group $(3 / 115 ; 2.6 \%)$ but in none of 117 ASA patients (Lindblad 1993), whereas in another trial, fatal MI was only found within the ASA group $(4 / 65 ; 6 \%)$ but never among the 60 patients of the placebo group (AITIA-S 1978).

\section{Comparison 1.9: Ischaemic stroke during follow-up period}

In the published data of all five trials (out of the six trials reporting about stroke occurrence) which indeed had strokes as outcome events, no details about the type of stroke were given, i.e. stroke due to ischaemia, to haemorrhage or of unknown type (Boysen 1988; Lindblad 1993; Harker 1992; AITIA-S 1978; Kretschmer 1990). Authors were contacted for clarification: in one study no actual address of the author could be traced (AITIA$S$ 1978). In this trial, one might speculate whether the fact that in the paragraph dealing with haemorrhagic complications, neither intracranial haemorrhages nor haemorrhagic strokes were mentioned in either treatment group, signified that all strokes mentioned were ischaemic strokes. In another trial, personal communication revealed that one of the nine strokes in the antiplatelet group $(\mathrm{N}=150)$ was a haemorrhagic stroke, whereas types of stroke remained unknown for both the remaining eight strokes in the antiplatelet group as well as all the 11 strokes within the placebo group $(\mathrm{N}=151)$ (Boysen 1988).

\section{Comparison 1.10: Intracranial haemorrhage}

Data on this outcome event are sparse. No conclusive data on 'intracranial haemorrhage' were available from publications of all trials. Personal communication revealed, that in one trial, one out of 150 ASA-treated patients (0.7\%) had a haemorrhagic stroke compared to none among 151 placebo-treated patients (0\%) (Boysen 1988). In another trial, the fact that no intracranial haemorrhage was reported in the section about adverse effects in the treatment group and the statement that 'none of the patients allocated to placebo had problems with bleeding ...' might indicate that there were no intracranial haemorrhages in either group. However, personal contact in an attempt to clarify this topic proved unsuccessful (AITIA-S 1978). Thus, a meaningful systematic metaanalysis regarding this outcome event cannot be performed so far.

\section{Comparison 1.11: Major extracranial haemorrhage}

Four trials reported data on extracranial haemorrhage in a way allowing categorisation (major or minor) as defined (Lindblad 1993; Harker 1992; AITIA-S 1978; Pratesi 1991). For a fifth RCT, data were based on personal communication (Boysen 1988). A Peto odds ratio of 1.71 with a $95 \% \mathrm{Cl}$ of 0.73 to 4.03 showed no significant difference. However, in all trials in which major extracranial haemorrhages occurred, they happened more often among patients in the antiplatelet group than in the control group. Thus, a statistically significant hazardous effect of antiplatelets might simply be missed due to a relatively small sample size. The types of major extracranial haemorrhage were gastrointestinal haemorrhages (AITIA-S 1978; Harker 1992) and local haemorrhages requiring surgery (Lindblad 1993; Harker 1992). Fatal extracranial haemorrhages were not reported.

\section{Comparison 1.12: Local haemorrhage requiring surgery}

Two trials published data about this outcome event (Harker 1992; Lindblad 1993). Data of a third trial were available by personal communication (Boysen 1988). A Peto odds ratio of 1.41 (95\% Cl 0.53 to 3.72 ) indicated no statistical significance between both treatment options.

\section{Comparison 1.13: Recurrent stenosis}

Recurrent ipsilateral stenosis greater than $50 \%$ was reported in three trials. Stenotic evaluation was performed by Doppler sonography (Lindblad 1993, Harker 1992) or by angiography (Pratesi 1991), respectively. A Peto odds ratio of 0.80 with a wide $95 \% \mathrm{Cl}$ of 0.42 to 1.52 indicated no statistically significant difference between patients treated with antiplatelet agents compared to those with control treatment. In one trial (Lindblad 1993), data on 'recurrent stenosis' were published separately and only on a subgroup of the entire study population. This may indicate a selection bias.

\section{Comparison 1.14: Occurrence or progression of contralateral stenosis}

No study reported on the occurrence or progression of contralateral stenosis. 


\section{Comparison 1.15: TIA or amaurosis fugax}

TIA or amaurosis fugax were reported in three trials (Lindblad 1993; Harker 1992; Boysen 1988). A Peto odds ratio of 0.96 with a $\mathrm{Cl}$ of 0.55 to 1.67 showed no statistical significance between the antiplatelet group and the control group.

\section{DISCUSSION}

Antiplatelet agents are beneficial to patients with atherosclerotic diseases of different types and who are at high risk of vascular events (ATT 2002). The purpose of this systematic review was to evaluate whether this beneficial effect is also true for patients after CEA. For this purpose, we have pooled data from studies using similar designs and analysed relevant clinical outcomes related to patients with occlusive cerebrovascular disease who needed CEA.

\section{Primary outcomes}

\section{Death (all causes)}

Despite a Peto odds ratio of 0.77 in favour of antiplatelets, these agents did not significantly alter the death rate in patients who were operated on the carotid artery. This is in contrast to the ATT 2002 report, that found a statistically significant $14 \%$ odds reduction (standard error (SE: 2) for the outcome 'all deaths' among the entire population of patients at high risks of occlusive vascular events. The same $14 \%$ odds reduction (SE: 5) was found for the subgroup of patients with previous stroke or TIA (ATT 2002). These seeming discrepancies might be due to the smaller sample size and the lower number of outcome events (six RCTs and 97 deaths) in this review compared to the ATT 2002 report (193 RCTs and 9605 deaths) (ATT 2002).

\section{Any stroke}

Antiplatelet therapy instead of no treatment or placebo avoids the occurrence of stroke according to our analysis. It reaches significance with a Peto OR of $0.58(\mathrm{Cl} 0.34$ to 0.98$)$, which is within the reported range of odds in the collaborative metaanalysis, where patients with previous stroke were prevented from further stroke by an OR of 0.77 (SE: 0.04) (ATT 2002). There was no significant heterogeneity between the trials; however, the confidence intervals were wide. By computing risk differences, one can estimate that out of 100 patients treated with antiplatelet drugs, three ( $\mathrm{Cl} 0.0$ to 7.0 ) could be saved from 'stroke' within the follow-up period (six to 27 months).

\section{Secondary outcomes}

\section{Vascular death and serious vascular events}

Neither for the outcome event 'vascular death' nor for the combined outcome 'serious vascular events' were statistically significant differences between antiplatelets and control shown in this review. The recently published collaborative meta-analysis reported that the allocation of antiplatelet therapy among patients at high risk of occlusive vascular events, reduced vascular mortality by about one sixth and the combined outcome 'any serious vascular event' by about one quarter (ATT 2002). The lower numbers in this review compared to the ATT 2002 report are most likely the reason for these differences.

\section{Death or dependency}

The outcome death or dependency after stroke was significantly reduced by antiplatelet treatment in one single trial. We urge caution when interpreting this finding as only data of one single RCT with a total of 232 patients were applicable for the evaluation of this outcome event (Lindblad 1993). Due to the small numbers, this result might be merely coincidental.

\section{Intra and extracranial haemorrhages}

For haemorrhage, no data were published on intracranial haemorrhage for either treatment group within all studies. A personal communication revealed one single haemorrhagic stroke out of 150 antiplatelet-treated CEA patients, compared to none out of 151 patients in the placebo group. Overall, the number of participants is unlikely to be sufficient to demonstrate any significant treatment-associated increase of intracranial bleedings. From other sources we know that the incidence of antiplateletassociated intracranial haemorrhages, i.e. 0.6 to $1.1 \%$ within three months after CEA plus ASA in a daily dose of 81 to $1300 \mathrm{mg}$ daily (ACE 1999) and $0.3 \%$ among patients with various manifestations of atherosclerosis (ATT 1994a), respectively, is low.

Both major extracranial bleedings as well as local haematoma requiring surgery were more frequent within the antiplatelet group of each of the three trials publishing data on this outcome but not statistically significant. This lack of significance may be due to the low number of participants $(\mathrm{N}=821)$.

In comparison to the ACE trial, where $1.9 \%$ of the patients suffered from major wound haematoma (defined as lengthened hospital stay, resulting in death or disability) within three months (ACE 1999) and to an overview of antiplatelet trials, where there was a very low, but significant excess of non-fatal bleedings in patients allocated to antiplatelet drugs versus controls (2.2\% versus $0.9 \%, 13$ per 1000 patients treated) to maintain arterial patency or vascular grafts (ATT 1994b), we did not detect an excess of haemorrhagic complications. With respect to these data, each RCT as well as this review itself appears to be underpowered to detect major extracranial bleeding differences. Nevertheless bleeding risks seem not of major concern, as on the one hand they seldom occur and on the other, lower doses of aspirin are advised for the future (ATT 2002).

\section{Myocardial infarction}

Regarding MI surprisingly no effect in favour of antiplatelets could be found in this systematic review. This finding contrasts with the results of the Mayo Trial (Mayo Trial 1992), where an excess of MIs in the CEA group without antiplatelets compared to medical treatment (including antiplatelets) alone, eventually resulted in an early and unplanned termination of the study. The lack of any effect in this review may be explained by the high heterogeneity between studies: in two RCTs MIs were only noted in the placebo group (Boysen 1988; Lindblad 1993), whereas another RCT reported an excess rate of Mls of six out of 100 patients in the antiplatelet group (AITIA-S 1978). The latter finding is in contrast to the commonly acknowledged MI-protective effect of antiplatelet drugs (ATT 1994a). The authors explained this finding by the fact that cardiovascular risk factors lost their initial balance between treatment groups, which led to a disproportional preponderance of risk factors in the antiplatelet group during the course of the study (AITIA-S 1978). As the number was small, the most accurate explanation, however, may be that the results were coincidental. 
Alternatively, they might reflect the recently revealed differences in mechanisms of thrombogenesis between different vascular beds (Rosenberg 1999). Furthermore, for stroke patients the incidence of post-stroke myocardial infarction is lower than that of recurrent stroke during the first years (Albers 2000). Assuming that these findings are also true for CEA patients, a lower MI incidence might have masked small but relevant beneficial effects of antiplatelets regarding MI in CEA patients.

From the other secondary outcome measure, such as recurrent stenosis, TIA or AF, no firm conclusions can be drawn due to the very small numbers. For recurrent stenosis there was a significant heterogeneity of trial results. Although a large meta-analysis of the antiplatelet collaborators showed a highly significant reduction in vascular occlusion of patients with revascularisation of coronary, or peripheral arteries, or with arteriovenous shunt or fistula for dialysis (ATT 1994a), this systematic review showed no beneficial effect of antiplatelet drugs for preventing carotid restenosis after CEA.

\section{The following limitations need mentioning}

For the majority of the 15 predefined outcome events, neither any beneficial nor any hazardous effects of antiplatelet therapy could be shown. Due to multiple testing, the results obtained might be coincidental and therefore should not be overestimated. Not all the RCTs included reached the same methodological standards concerning blinding, randomisation or outcome assessment. Therefore, selection bias in patient recruitment and treatment allocation, or detection bias in outcome events could not be excluded.

Furthermore, the trials were presumably too small to detect moderate but important benefits or hazards of antiplatelet drugs. Two of the four RCTs with ASA as antiplatelet agent used a daily dose of $1300 \mathrm{mg}$, and $990 \mathrm{mg}$ plus dipyridamole $225 \mathrm{mg}$ b.i.d., respectively. Nowadays, there is a trend towards lower dosages (ATT 2002; ACE 1999), which is why the results of these two trials seem difficult to be applied to present day practice. Thus, the negative results in respect of antiplatelet-associated bleeding hazards should be interpreted cautiously.

Stroke, rather than MI or death, might be the outcome that seems to be prevented primarily by antiplatelets drugs after CEA. Stroke has also been proposed 'likely to be the most relevant determinant of an antiplatelet agent's value to a patient who recently sustained a stroke or a TIA' (Albers 2000). Assuming that this is true for CEA patients, our results might indicate that, from a clinical point of view, using antiplatelets after CEA rather than withholding them is probably preferable.

\section{AUTHORS' CONCLUSIONS}

\section{Implications for practice}

There is some suggestion that antiplatelet drugs reduce the odds of death after carotid endarterectomy, although the results are inconclusive and there is a possibility that antiplatelet drugs increase death. Antiplatelet drugs reduce the odds of stroke after carotid endarterectomy. There is a suggestion that antiplatelets after carotid endarterectomy may increase the odds of haemorrhage, but there are currently too few data to quantify this effect. Therefore, from a clinical point of view, there is no reason to withhold antiplatelet drugs from patients undergoing CEA. Our data do not allow the recommendation for a precise dose, as most trials used high doses of aspirin alone or in combination with other antiplatelet drugs.

\section{Implications for research}

The results of this systematic review as well as those of the Mayo Trial indicated that antiplatelet therapy appears superior to placebo after CEA; hazardous effects of antiplatelets were not shown so far. Thus, testing antiplatelet drugs against placebo in a future RCT appears not to be an issue. Because antiplatelet drugs so far predominantly meant ASA, and as the protective effect (regarding stroke, MI, vascular death) seems to be low, a future RCT in CEA patients should test ASA (in a daily dosage of 80 to 325 $\mathrm{mg}$ in respect to the ACE trial) against a different, potentially more effective antiplatelet drug. Further research will also have to focus on the effects of combinations of ASA with other antiplatelet drugs.

\section{ACKNOWLEDGEMENTS}

We thank Hazel Fraser and Brenda Thomas for providing us with lists of potentially relevant trials from the Cochrane Stroke Group's Register and for enormous editorial help. We like to thank Kathi Schweikert for her contribution in developing the protocol. We are very grateful to $G$ Boysen for her perusal of the source data of the 'Danish very-low dose aspirin after carotid endarterectomy trial'. We are very thankful to $P$ Sandercock for many helpful comments while we wrote the review. In addition, we like to thank L Candelise, G Venables, C Sudlow, S Lewis, and C Graham for important suggestions on an earlier draft of this review.

If anyone knows of trials that we have omitted, we would be grateful if they could contact us. 


\section{RE F E R E N C E S}

\section{References to studies included in this review}

AITIA-S 1978 \{published data only\}

Fields WS, Lemak NA. Controlled trial of Aspirin in cerebral ischemia; study design, surveillance, and results. In: Breddin K, Dorndorf W, Loew D, Marx R editor(s). Acetylsalicylic acid in cerebral ischemia and coronary heart disease. First Edition. Stuttgartt, New York: Schattauer, 1978:85-91.

* Fields WS, Lemak NA, Frankowski RF, Hardy RJ. Controlled trial of aspirin in cerebral ischemia. Part II: surgical group. Stroke 1978;9(4):309-319.

Lemak NA, Fields WS, Gary HE Jr. Controlled trial of aspirin in cerebral ischemia: an addendum. Neurology 1986;36:705-710.

\section{Boysen 1988 \{published data only\}}

Boysen G. Danish very-low dose aspirin after carotid endarterectomy trial. Personal communication August 2001.

* Boysen G, Sorensen PS, Juhler M, Andersen AR, Boas J, Olsen JS, Joensen P. Danish very-low dose aspirin after carotid endarterectomy trial. Stroke 1988;19(10):1211-1215.

Boysen G, Sorensen PS, Juhler M, Andersen AR, Boas J, Olsen JS, Joensen P. Low-dose aspirin after carotid surgery. Stroke. 1988; Vol. 19:148.

\section{Harker 1992 \{published data only\}}

Antithrombotic Trialists' Collaboration. Collaborative metaanalysis of randomised trials of antiplatelet therapy for prevention of death, myocardial infarction, and stroke in high risk patients. BMJ 2002;324:71-86.

* Harker LA, Bernstein EF, Dilley RB, Scala TE, Sise MJ, Hye RJ, et al. Failure of aspirin plus dipyridamole to prevent restenosis after carotid endarterectomy. Annals of Internal Medicine 1992;116(9):731-736.

\section{Kretschmer 1990 \{published data only\}}

* Antithrombotic Trialists' Collaboration. Collaborative metaanalysis of randomised trials of antiplatelet therapy for prevention of death, myocardial infarction, and stroke in high risk patients. $B M J$ 2002;324:71-86

Bischoff G, Pratschner T, Kail M, et al. Anticoagulants, antiaggregants or nothing following carotid endarterectomy?. European Journal of Vascular Surgery 1993;7:364-369.

Kretschmer G, Pratschner T, Prager M, et al. Antiplatelet treatment prolongs survival after carotid endarterectomy. Analysis of the clinical series followed by a controlled trial. Annals of Surgery 1990;211:317-322.

Pratschner T, Kretschmer P, Prager M, et al. Antiplatelet therapy following carotid bifurcation endarterectomy. Evaluation of a controlled clinical trial. Prognostic significance of histologic plaque examination on behalf of survival. European Journal of Vascular Surgery 1990;4:285-289.

\section{Lindblad 1993 \{published data only\}}

Hansen F, Lindblad B, Persson NH, Bergquist D. Can recurrent stenosis after carotid endarterectomy be prevented by lowdose acetylsalicylic acid? A double-blind, randomised and placebo-controlled study. European Journal of Vascular Surgery 1993;7(4):380-385.

* Lindblad B, Persson NH, Takolander R, Bergquist D. Does lowdose acetylsalicylic acid prevent stroke after carotid surgery? A double-blind, placebo-controlled randomized trial. Stroke 1993;24(8):1125-1128.

\section{Pratesi 1991 \{published data only\}}

Pratesi C, Pulli R, Milanesi G, Lavezzari M, Pamparana F, Bertini D. Indobufen versus placebo in the prevention of restenosis after carotid endarterectomy: a double-blind pilot study. Journal of International Medical Research 1991;19(3):202-209.

\section{References to studies excluded from this review}

Findlay 1985 \{published data only\}

* Findlay JM, Lougheed WM, Gentili F, Walker PM, Glynn MF, Houle S. Effect of perioperative platelet inhibition on postcarotid endarterectomy mural thrombus formation. Results of a prospective randomized controlled trial using aspirin and dipyridamole in humans. Journal of Neurosurgery 1985;63(5):693-698.

\section{McCollum 1993 \{published and unpublished data\}}

McCollum C. A double blind placebo controlled study to assess the effect of platelet inhibition on thrombus formation and restenosis following carotid endarterectomy. National Research Register 1993:Publication ID: C0300282.

\section{Pedrini 1988 \{published data only\}}

Catani L, Vitacchiano G, Scatigna M, Monetti N, Pedrini L, Gugliotta L. Ticlopidine and prevention of platelet accumulation in carotid endarterectomy. Evaluation with Indium-111 labeled platelets. Thrombosis and Haemostasis 1987;58:169.

Pedrini L, Gugliotta L, Monetti N, Vitacchiano G, Catani L, Guidalotti RL, Scatigna M. Platelet adhesion in carotid endarterectomy. CV World report 1988;1:93-96.

\section{Additional references}

\section{ACE 1999}

Taylor DW, Barnett HJ, Haynes RB, Ferguson GG, Sackett DL, Thorpe KE, Simard D, Silver FL, Hachinski V, Clagett GP, Barnes R, Spence JD. Low-dose and high-dose acetylsalicylic acid for patients undergoing carotid endarterectomy: a randomised controlled trial. ASA and Carotid Endarterectomy (ACE) Trial Collaborators. Lancet 1999;353(9171):2179-84. 


\section{Albers 2000}

Albers GW. Choice of endpoints in antiplatelet trials. Which outcome is relevant for stroke patients?. Neurology 2000;54:1022-1028.

\section{ATT 1994a}

Antiplatelet Trialists' Collaboration. Collaborative overview of randomised trials of antiplatelet therapy - I: Prevention of death, myocardial infarction, and stroke by prolonged antiplatelet therapy in various categories of patients. BMJ 1994;308:81-108.

\section{ATT 1994b}

Antiplatelet Trialists' Collaboration. Collaborative overview of randomised trials of antiplatelet therapy - II: Maintenance of vascular graft or arterial patency by antiplatelet therapy. BMJ 1994;308:159-168.

\section{ATT 1994c}

Antiplatelet Trialists' Collaboration. Collaborative overview of randomised trials of antiplatelet therapy - III: Reduction in venous thrombosis and pulmonary embolism by antiplatelet prophylaxis among surgical and medical patients. $B M J$ 1994;308:235-246.

\section{ATT 2002}

Antithrombotic Trialists' Collaboration. Collaborative metaanalysis of randomised trials of antiplatelet therapy for prevention of death, myocardial infarction, and stroke in high risk patients. BMJ 2002;324:71-86.

\section{Chambers 2002}

Chambers BR, You RX, Donnan GA. Carotid endarterectomy for asymptomatic carotid stenosis. Cochrane Database of Systematic Reviews 2002, Issue 3. [Art. No.: CD001923. DOI: 10.1002/14651858.CD001923.pub2]

\section{Cina 2002}

Cina CS, Clase CM, Haynes RB. Carotid endarterectomy for symptomatic carotid stenosis. Cochrane Database of Systematic Reviews 2002, Issue 3. [Art. No.: CD001081. DOI: 10.1002/14651858.CD001081]

\section{de Bray 1995}

de Bray JM, Glatt B. Quantification of Atheromatous Stenosis in the Extracranial Internal Carotid Artery. Cerebrovascular Diseases 1995;5:414-426.

\section{CHARACTERISTICS OF STUDIES}

Characteristics of included studies [ordered by study ID]

\section{ECST 1998}

European Carotid Surgery Trialists' Collaborative Group. Randomised trial of endarterectomy for recently symptomatic carotid stenosis: final results of the MRC European Carotid Surgery Trial (ECST). Lancet 1998;351:1379-1387.

\section{IST 1997}

International Stroke Trial Group. The International Stroke Trial (IST): a randomised trial of aspirin, subcutaneous heparin, both, or neither among 19435 patients with acute ischemic stroke. Lancet 1997;349:1569-1581.

\section{Jadad 1996}

Jadad AR, Moore RA, Carrol D, Jenkinson C, Reynolds DJM, Gravaghan DJ, et al. Assessing the quality of reports of randomized clinical trials: is blinding necessary?. Controlled Clinical Trials 1996;17:1-12.

\section{Mayo Trial 1992}

Mayo Asymptomatic Carotid Endarterectomy Study Group. Results of a randomized controlled trial of carotid endarterectomy for asymptomatic carotid stenosis. Mayo Clinic Proceedings 1992;67:513-518.

\section{NASCET 1991}

North American Symptomatic Carotid Endarterectomy Trial (NASCET) Collaborators. Beneficial effect of carotid endarterectomy in symptomatic patients with highgrade carotid stenosis. New England Journal of Medicine 1991;325:445-453.

\section{NASCET 1998}

North American Symptomatic Carotid Endarterectomy Trial Collaborators. Benefit of carotid endarterectomy in patients with symptomatic moderate or severe stenosis. New England Journal of Medicine 1998;339(20):1415-1425.

\section{Rosenberg 1999}

Rosenberg RD. Vascular beds-specific hemostasis and hypercoagulable states. New England Journal of Medicine 1999;340(20):1555-1564.

\section{Timsit 1992}

Timsit SG, Sacco RL, Mohr JP, et al. Early clinical differentiation of cerebral infarction from severe atherosclerotic stenosis and cardioembolism. Stroke 1992;23:486-491.

* Indicates the major publication for the study

AITIA-S 1978

\begin{tabular}{ll}
\hline Methods & RCT \\
\hline Participants & $\begin{array}{l}125 \text { patients } \\
\text { All with symptomatic stenosis }\end{array}$
\end{tabular}




\section{AITIA-S 1978 (Continued)}

Interventions $\quad 65$ patients with ASA $1300 \mathrm{mg} / \mathrm{d}$ versus 60 patients with placebo Onset of medication 5 days after CEA

\begin{tabular}{ll}
\hline Outcomes & Death, vascular death, major extracranial haemorrhage, MI, amaurosis fugax \\
\hline Notes & $\begin{array}{l}\text { Randomisation and blinding not described in detail } \\
5 \text { drop outs }\end{array}$
\end{tabular}

\section{Risk of bias}

\begin{tabular}{lll}
\hline Bias & Authors' judgement & Support for judgement \\
\hline Allocation concealment? & Unclear risk & B - Unclear \\
\hline
\end{tabular}

Boysen 1988

\begin{tabular}{ll}
\hline Methods & RCT \\
\hline Participants & $\begin{array}{l}\text { Symptomatic stenosis: } 292 \\
\text { Asymptomatic stenosis: } 9\end{array}$ \\
\hline Interventions & $\begin{array}{l}150 \text { patients with ASA } 50 \text { to } 100 \mathrm{mg} / \mathrm{d} \text { versus } 151 \text { patients with placebo } \\
\text { Onset of medication: } 3 \text { months after CEA }\end{array}$ \\
\hline Outcomes & $\begin{array}{l}\text { Death, vascular death, stroke, TIA, MI, major extracranial haemorrhage, local haemorrhage requiring } \\
\text { surgery }\end{array}$ \\
\hline Notes & $\begin{array}{l}\text { Randomisation and blinding appropriate (according to Jadad 1996) } \\
61 \text { drop outs } \\
\text { Data about 'all death', the nature of the reported strokes, major extracranial haemorrhage and local } \\
\text { haemorrhage requiring surgery were obtained by personal communication }\end{array}$
\end{tabular}

\section{Risk of bias}

\begin{tabular}{lll}
\hline Bias & Authors' judgement & Support for judgement \\
\hline Allocation concealment? & Low risk & A - Adequate \\
\hline
\end{tabular}

\section{Harker 1992}

\begin{tabular}{ll}
\hline Methods & RCT \\
\hline Participants & $\begin{array}{l}163 \text { patients } \\
\text { Some patients had symptomatic, some had asymptomatic stenosis; no details on numbers }\end{array}$ \\
\hline Interventions & $\begin{array}{l}83 \text { patients with ASA } 990 \mathrm{mg} / \mathrm{d}+\text { dipyridamole } 225 \mathrm{mg} / \mathrm{d} \text { versus } 80 \text { patients with placebo } \\
\text { Onset of medication: } 12 \text { hours before CEA }\end{array}$ \\
\hline Outcomes & $\begin{array}{l}\text { Death, vascular death, stroke, restenosis, TIA, major extracranial haemorrhage, local haemorrhage re- } \\
\text { quiring surgery }\end{array}$ \\
\hline Notes & Randomisation and blinding appropriate (according to Jadad 1996)
\end{tabular}


Harker 1992 (Continued)

22 withdrawals, 23 other drop outs

\section{Risk of bias}

\begin{tabular}{lll}
\hline Bias & Authors' judgement & Support for judgement \\
\hline Allocation concealment? & Low risk & A-Adequate \\
\hline
\end{tabular}

Kretschmer 1990

\begin{tabular}{ll}
\hline Methods & RCT \\
\hline Participants & 66 patients \\
& Symptomatic stenosis: $41 ;$ \\
& Asymptomatic stenosis: 25 \\
\hline
\end{tabular}

$\begin{array}{ll}\text { Interventions } & 32 \text { patients with ASA } 1000 \mathrm{mg} / \mathrm{d} \text { versus } 34 \text { patients with 'no anti-aggregating medication' } \\ \text { Onset of medication: } 2 \text { days before CEA }\end{array}$

\begin{tabular}{ll}
\hline Outcomes & Death, vascular death, stroke \\
\hline Notes & 'Adaptive randomisation' \\
& No blinding \\
& No placebo as control \\
& No information on drop outs or on withdrawals \\
\hline
\end{tabular}

\section{Risk of bias}

\begin{tabular}{lll}
\hline Bias & Authors' judgement & Support for judgement \\
\hline Allocation concealment? & Unclear risk & B - Unclear \\
\hline
\end{tabular}

Lindblad 1993

\begin{tabular}{ll}
\hline Methods & RCT \\
\hline Participants & 232 patients \\
& Symptomatic stenosis: 215 \\
& Asymptomatic stenosis: 17 \\
\hline
\end{tabular}

$\begin{array}{ll}\text { Interventions } & 117 \text { patients with ASA } 75 \mathrm{mg} / \mathrm{d} \text { versus } 115 \text { patients with placebo } \\ \text { Onset of medication: the evening before CEA }\end{array}$

Deatcomes stroke, dependency recovery, fatal MI, TIA (including amaurosis fugax), local haemorrhage re-
quiring surgery

Notes Randomisation and blinding not described in detail

21 dropouts

Data on re-stenosis only available for 174 patients

\section{Risk of bias}


Lindblad 1993 (Continued)

Allocation concealment? Unclear risk B-Unclear

Pratesi 1991

\begin{tabular}{ll} 
Methods & RCT \\
\hline Participants & $\begin{array}{l}20 \text { patients } \\
\text { all with symptomatic stenosis }\end{array}$
\end{tabular}

\begin{tabular}{ll}
\hline Interventions & 10 patients with indobufen $400 \mathrm{mg} / \mathrm{d}$ versus 10 patients with placebo \\
Onset of medication: 2 days before CEA
\end{tabular}

Onset of medication: 2 days before CEA

\begin{tabular}{ll}
\hline Outcomes & Restenosis, death, vascular death, stroke, major extracranial haemorrhage \\
\hline Notes & $\begin{array}{l}\text { No details on randomisation procedure in the paper, but it was adequately (according to Jadad 1996) } \\
\text { described in a letter (personal communication) } \\
\text { No information on withdrawals or drop outs }\end{array}$ \\
\hline
\end{tabular}

\section{Risk of bias}

\begin{tabular}{lll}
\hline Bias & Authors' judgement & Support for judgement \\
\hline Allocation concealment? & Low risk & A-Adequate \\
\hline
\end{tabular}

ASA: acetylsalicylic acid

CEA: carotid endarterectomy

MI: myocardial infarction

$\mathrm{RCT}$ : randomised controlled trial

TIA: transient ischaemic attack

Characteristics of excluded studies [ordered by study ID]

\begin{tabular}{ll}
\hline Study & Reason for exclusion \\
\hline Findlay 1985 & RCT antiplatelets versus placebo, but follow-up period not specified and antiplatelets for $<30$ days \\
\hline McCollum 1993 & No data available (personal communication) \\
\hline Pedrini 1988 & RCT, but treatment $<30$ days \\
\hline
\end{tabular}

$\mathrm{RCT}$ : randomised controlled trial

\section{DATA AND ANALYSES}


Comparison 1. Antiplatelets versus control

\begin{tabular}{|c|c|c|c|c|}
\hline Outcome or subgroup title & $\begin{array}{l}\text { No. of } \\
\text { studies }\end{array}$ & $\begin{array}{l}\text { No. of } \\
\text { partici- } \\
\text { pants }\end{array}$ & Statistical method & Effect size \\
\hline 1 Death (all causes) & 6 & 907 & $\begin{array}{l}\text { Peto Odds Ratio (Peto, Fixed, } \\
95 \% \mathrm{Cl} \text { ) }\end{array}$ & $0.77[0.48,1.24]$ \\
\hline $\begin{array}{l}2 \text { Stroke (any stroke during the follow-up peri- } \\
\text { od) }\end{array}$ & 6 & 907 & $\begin{array}{l}\text { Peto Odds Ratio (Peto, Fixed, } \\
95 \% \mathrm{Cl} \text { ) }\end{array}$ & $0.58[0.34,0.98]$ \\
\hline 3 Vascular death & 5 & 675 & $\begin{array}{l}\text { Peto Odds Ratio (Peto, Fixed, } \\
95 \% \mathrm{Cl} \text { ) }\end{array}$ & $0.96[0.54,1.71]$ \\
\hline 4 Stroke or vascular death & 5 & 675 & $\begin{array}{l}\text { Peto Odds Ratio (Peto, Fixed, } \\
95 \% \mathrm{Cl} \text { ) }\end{array}$ & $0.81[0.51,1.30]$ \\
\hline $\begin{array}{l}5 \text { Serious vascular events during follow-up } \\
\text { period }\end{array}$ & 5 & 675 & $\begin{array}{l}\text { Peto Odds Ratio (Peto, Fixed, } \\
95 \% \mathrm{Cl} \text { ) }\end{array}$ & $0.78[0.49,1.22]$ \\
\hline $\begin{array}{l}6 \text { Death or dependency at the end of follow } \\
\text { up }\end{array}$ & 1 & 232 & $\begin{array}{l}\text { Peto Odds Ratio (Peto, Fixed, } \\
95 \% \mathrm{Cl} \text { ) }\end{array}$ & $0.28[0.13,0.62]$ \\
\hline 7 Myocardial infarction (all) & 3 & 446 & $\begin{array}{l}\text { Peto Odds Ratio (Peto, Fixed, } \\
95 \% \mathrm{Cl} \text { ) }\end{array}$ & $1.42[0.40,5.07]$ \\
\hline 8 Non-fatal myocardial infarction & 3 & 447 & $\begin{array}{l}\text { Peto Odds Ratio (Peto, Fixed, } \\
95 \% \mathrm{Cl} \text { ) }\end{array}$ & $0.48[0.10,2.42]$ \\
\hline 9 Ischaemic stroke during follow-up period & 1 & 20 & $\begin{array}{l}\text { Peto Odds Ratio (Peto, Fixed, } \\
95 \% \mathrm{Cl} \text { ) }\end{array}$ & $0.0[0.0,0.0]$ \\
\hline 10 Intracranial haemorrhage & 1 & 301 & $\begin{array}{l}\text { Peto Odds Ratio (Peto, Fixed, } \\
95 \% \mathrm{Cl} \text { ) }\end{array}$ & $7.44[0.15,374.88]$ \\
\hline 11 Major extracranial haemorrhage & 5 & 841 & $\begin{array}{l}\text { Peto Odds Ratio (Peto, Fixed, } \\
95 \% \mathrm{Cl} \text { ) }\end{array}$ & $1.71[0.73,4.03]$ \\
\hline 12 Local haemorrhage requiring surgery & 3 & 696 & $\begin{array}{l}\text { Peto Odds Ratio (Peto, Fixed, } \\
95 \% \mathrm{Cl} \text { ) }\end{array}$ & $1.41[0.53,3.72]$ \\
\hline 13 Recurrent stenosis & 3 & 357 & $\begin{array}{l}\text { Peto Odds Ratio (Peto, Fixed, } \\
95 \% \mathrm{Cl} \text { ) }\end{array}$ & $0.80[0.42,1.52]$ \\
\hline $\begin{array}{l}14 \text { Contralateral stenosis (occurrence/pro- } \\
\text { gression) }\end{array}$ & 0 & 0 & $\begin{array}{l}\text { Peto Odds Ratio (Peto, Fixed, } \\
95 \% \mathrm{Cl} \text { ) }\end{array}$ & $0.0[0.0,0.0]$ \\
\hline 15 TIA or amaurosis fugax & 3 & 696 & $\begin{array}{l}\text { Peto Odds Ratio (Peto, Fixed, } \\
95 \% \mathrm{Cl} \text { ) }\end{array}$ & $0.96[0.55,1.67]$ \\
\hline
\end{tabular}


Analysis 1.1. Comparison 1 Antiplatelets versus control, Outcome 1 Death (all causes).

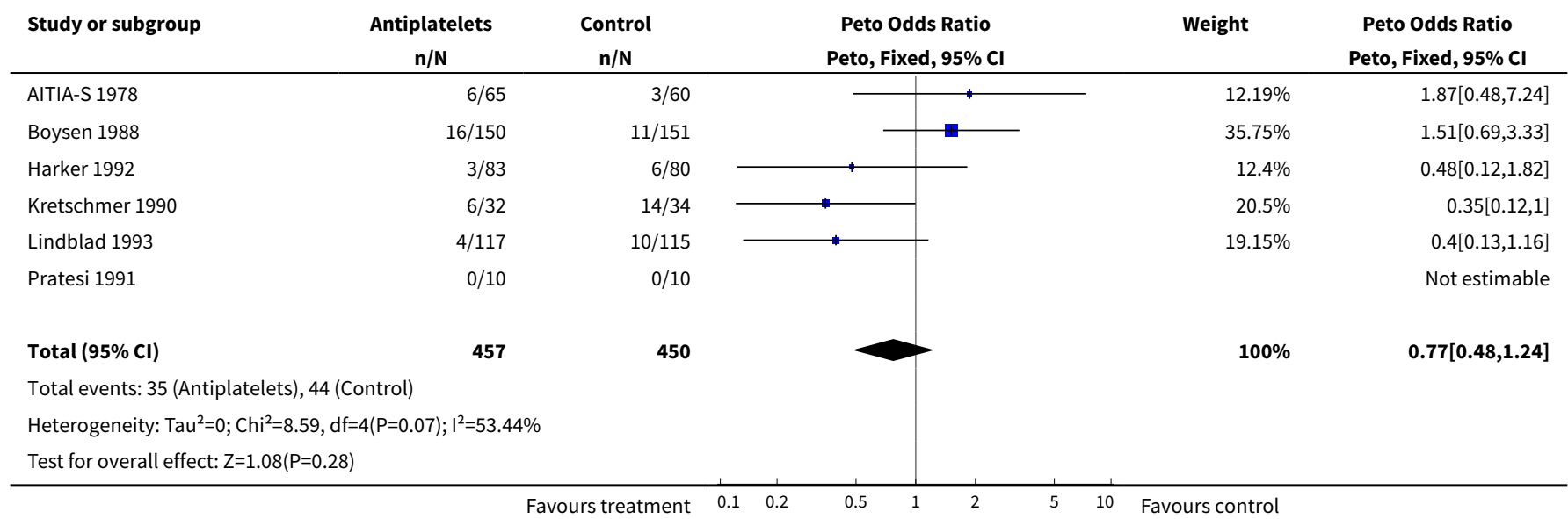

Analysis 1.2. Comparison 1 Antiplatelets versus control, Outcome 2 Stroke (any stroke during the follow-up period).

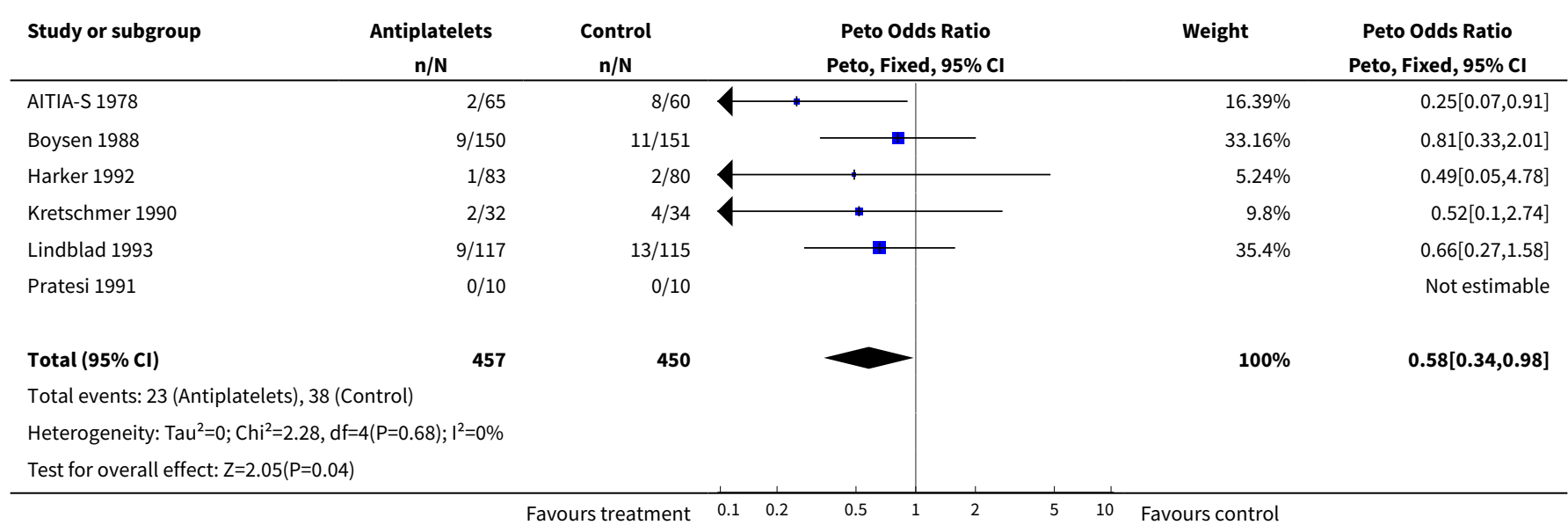

Analysis 1.3. Comparison 1 Antiplatelets versus control, Outcome 3 Vascular death.

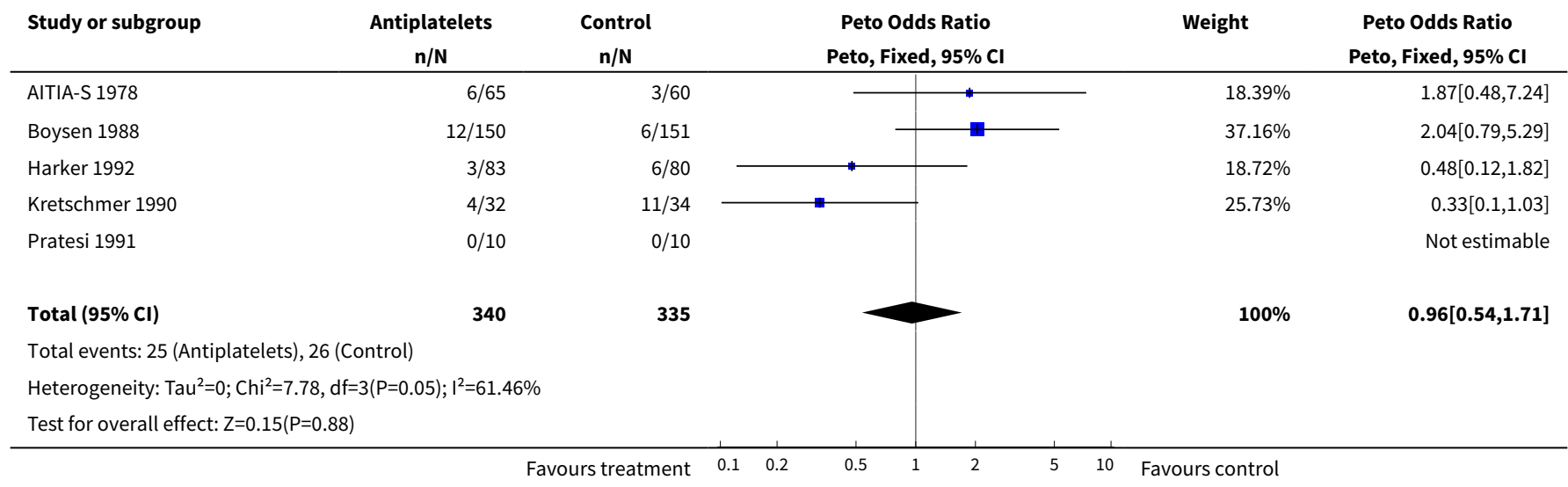


Analysis 1.4. Comparison 1 Antiplatelets versus control, Outcome 4 Stroke or vascular death.

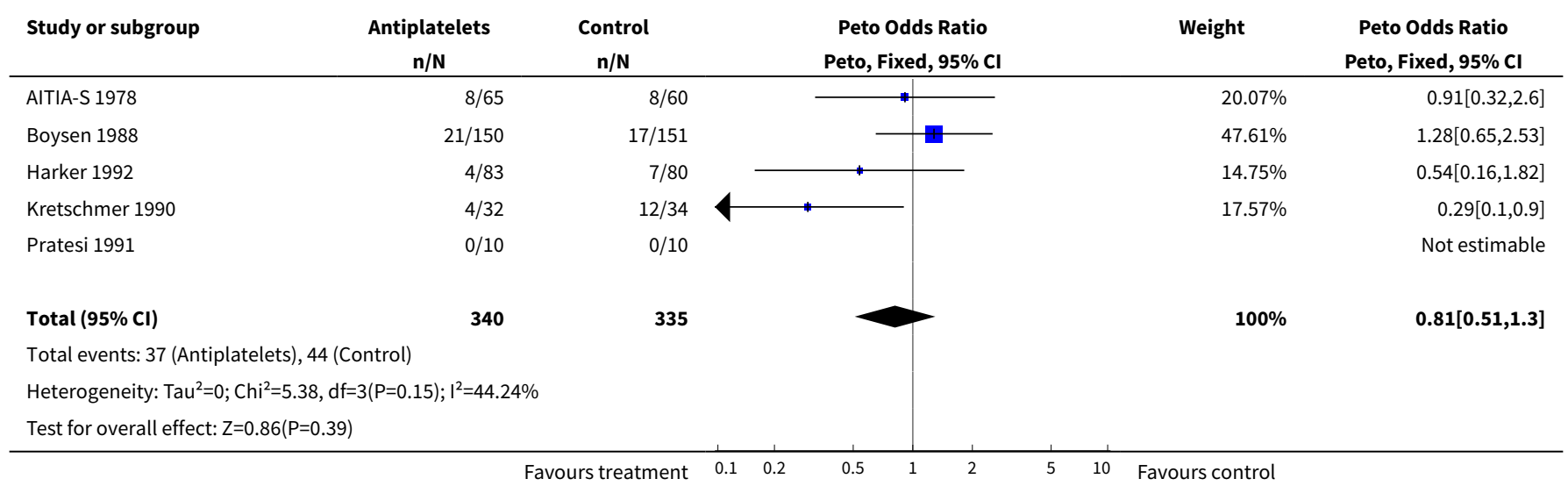

Analysis 1.5. Comparison 1 Antiplatelets versus control, Outcome 5 Serious vascular events during follow-up period.

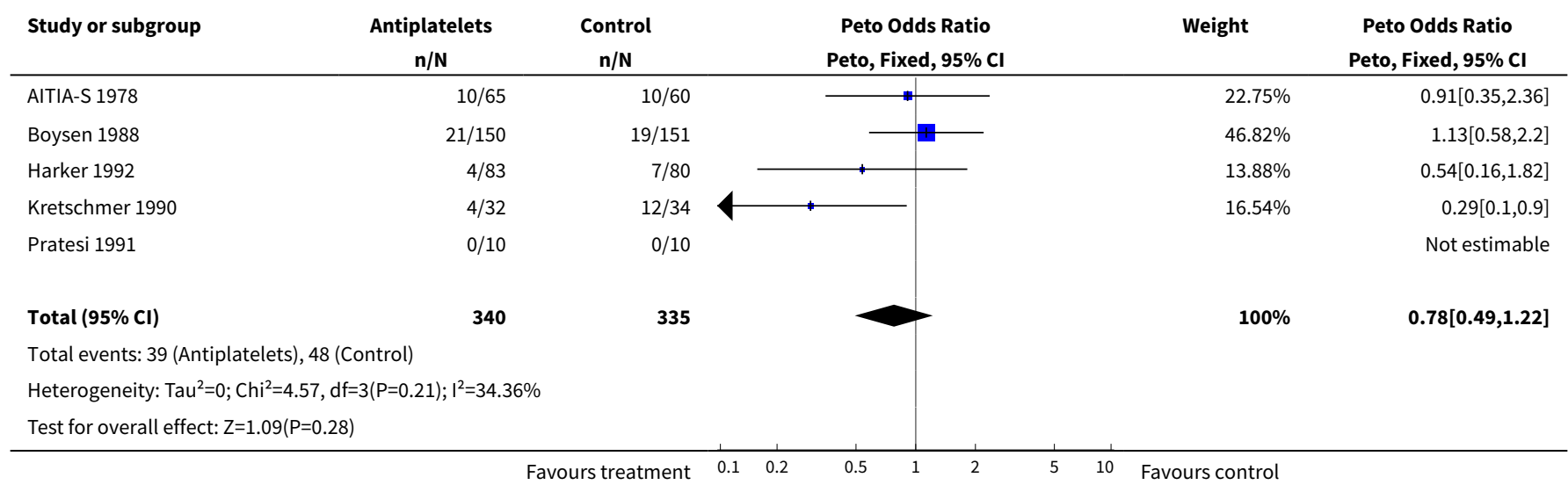

\section{Analysis 1.6. Comparison 1 Antiplatelets versus control, Outcome 6 Death or dependency at the end of follow up.}

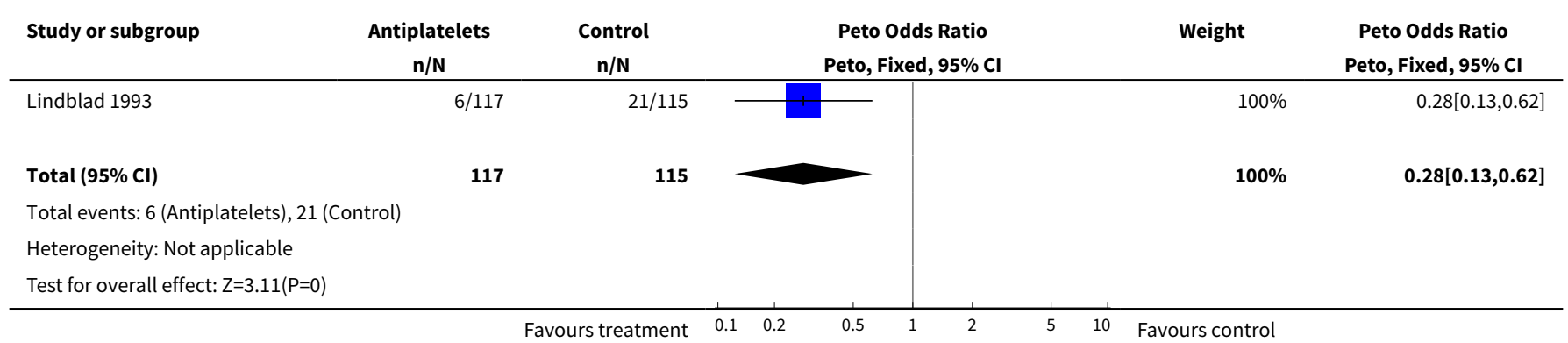


Analysis 1.7. Comparison 1 Antiplatelets versus control, Outcome 7 Myocardial infarction (all).

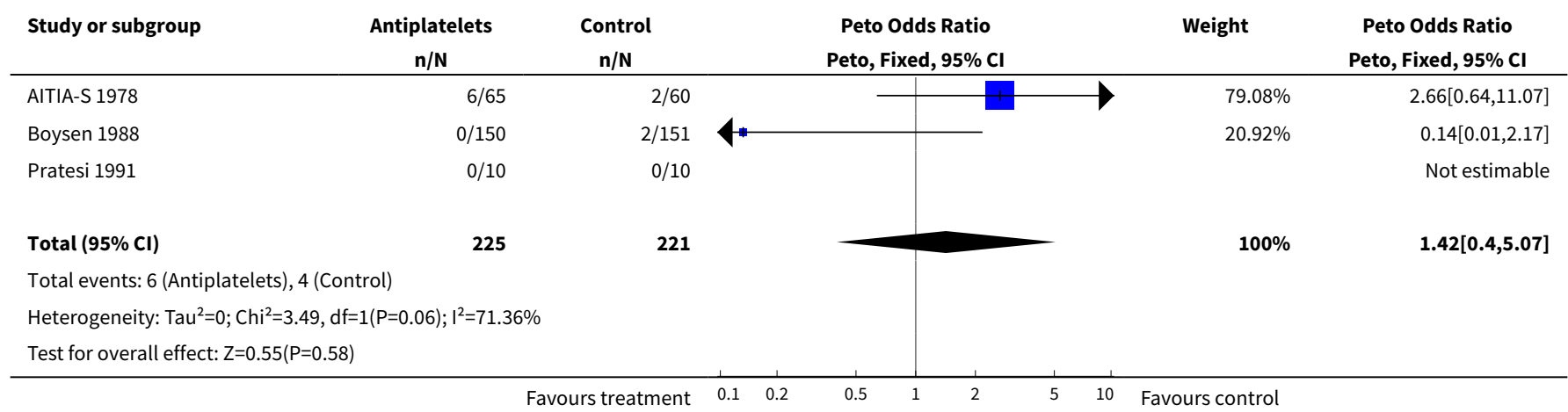

\section{Analysis 1.8. Comparison 1 Antiplatelets versus control, Outcome 8 Non-fatal myocardial infarction.}

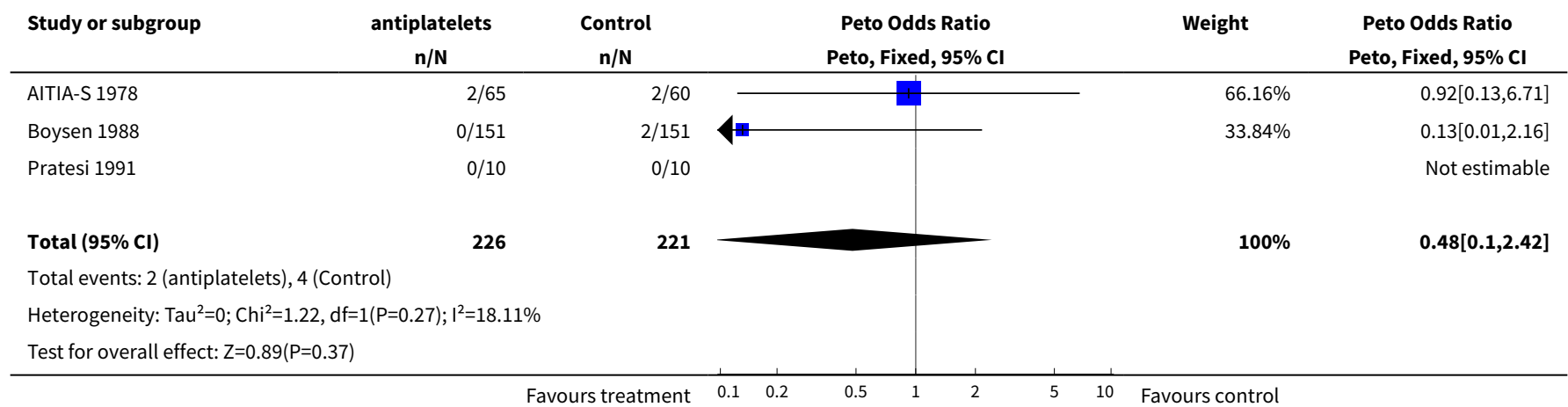

\section{Analysis 1.9. Comparison 1 Antiplatelets versus control, Outcome 9 Ischaemic stroke during follow-up period.}

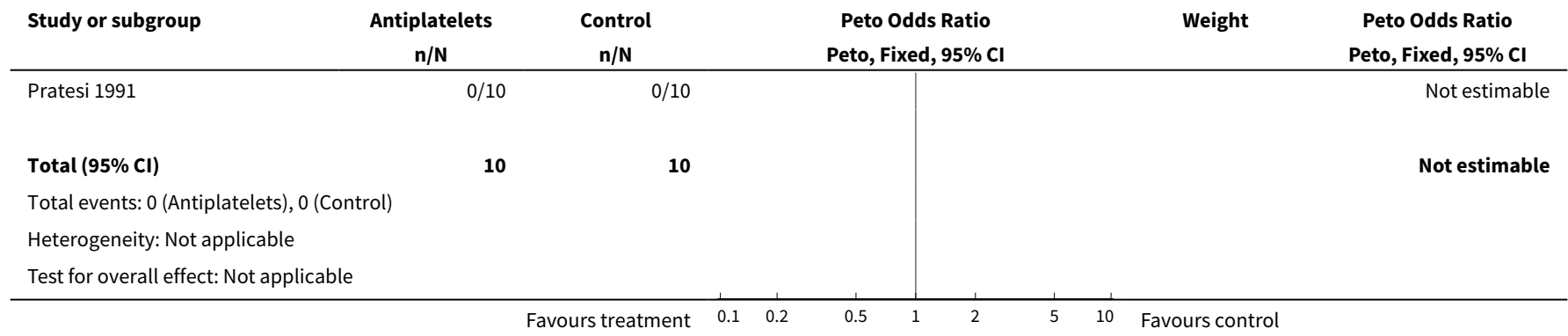

Analysis 1.10. Comparison 1 Antiplatelets versus control, Outcome 10 Intracranial haemorrhage.

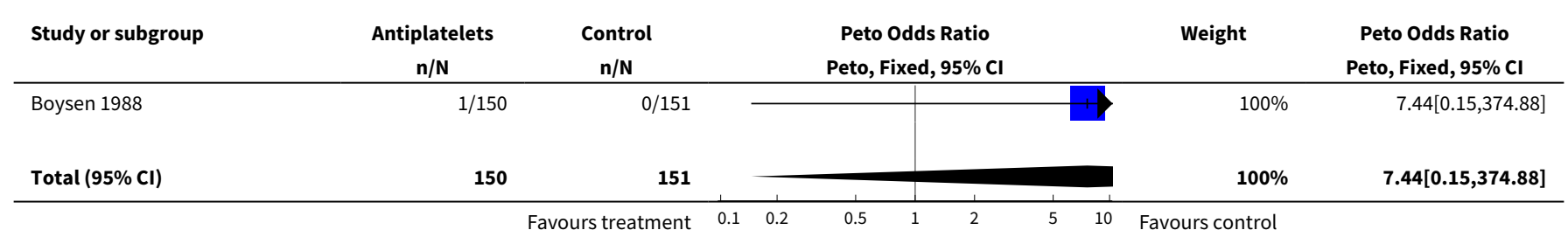




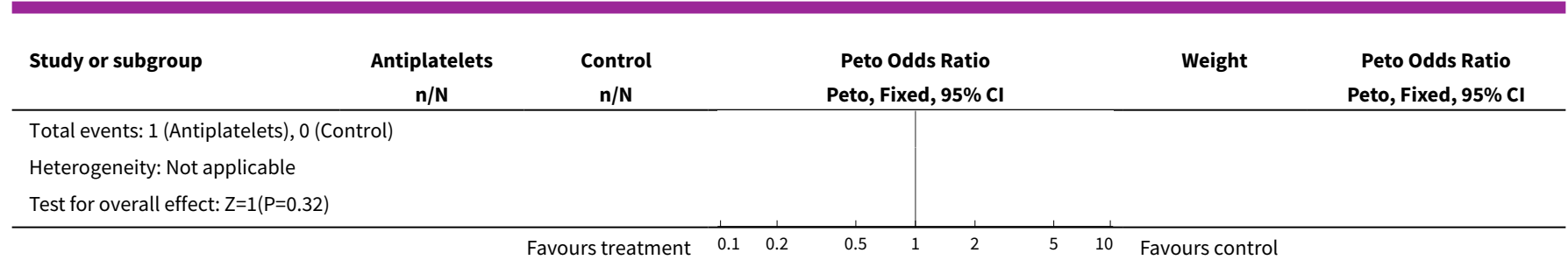

\section{Analysis 1.11. Comparison 1 Antiplatelets versus control, Outcome 11 Major extracranial haemorrhage.}

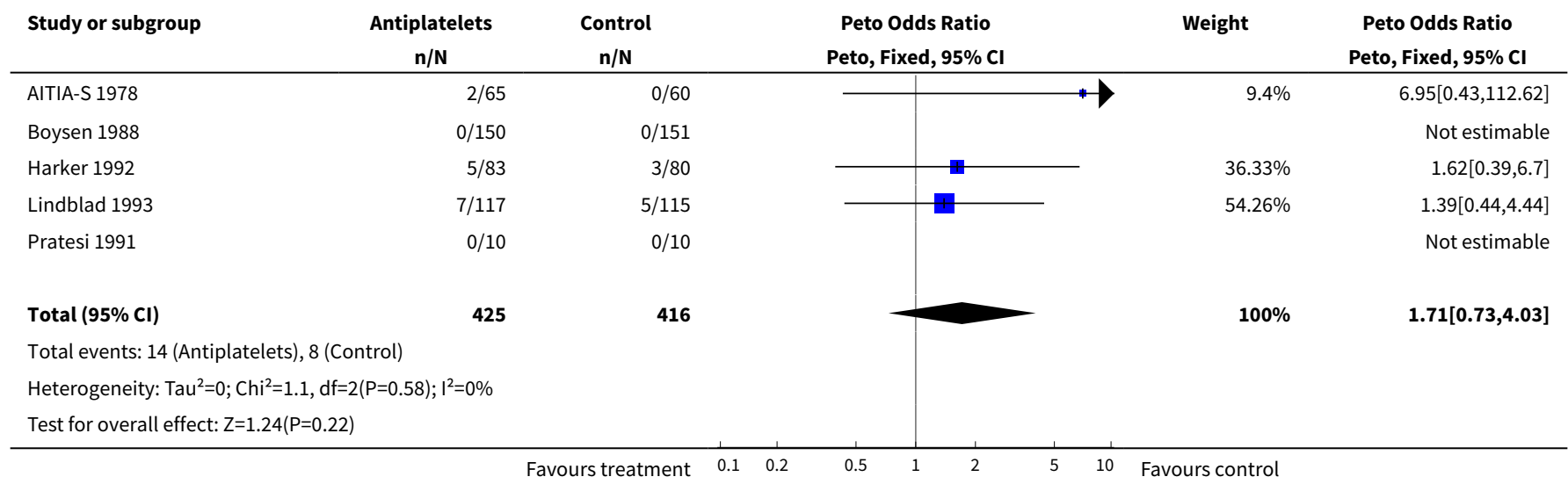

Analysis 1.12. Comparison 1 Antiplatelets versus control, Outcome 12 Local haemorrhage requiring surgery.

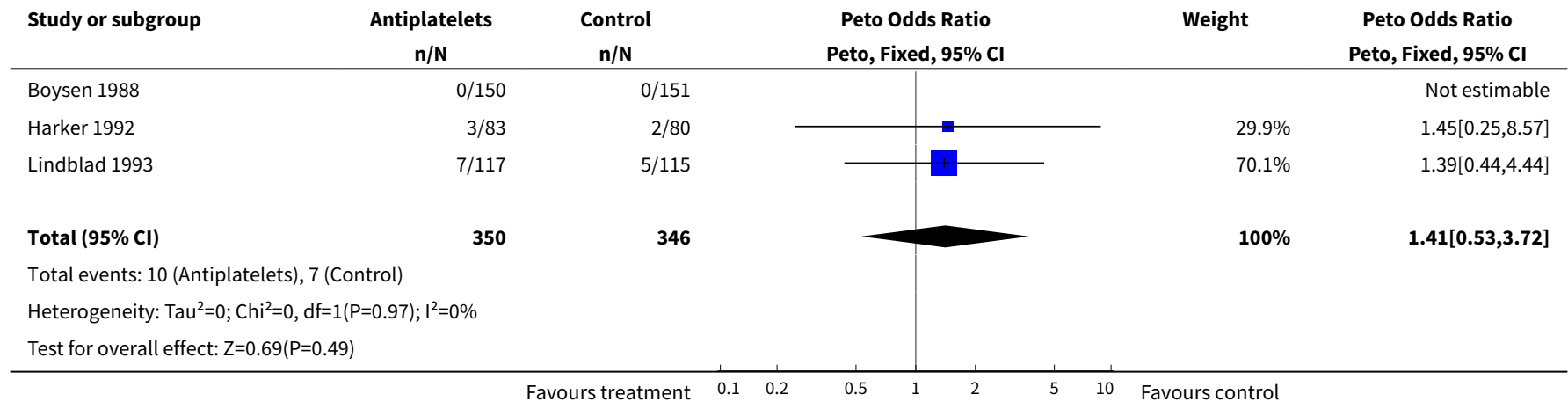

Analysis 1.13. Comparison 1 Antiplatelets versus control, Outcome 13 Recurrent stenosis.

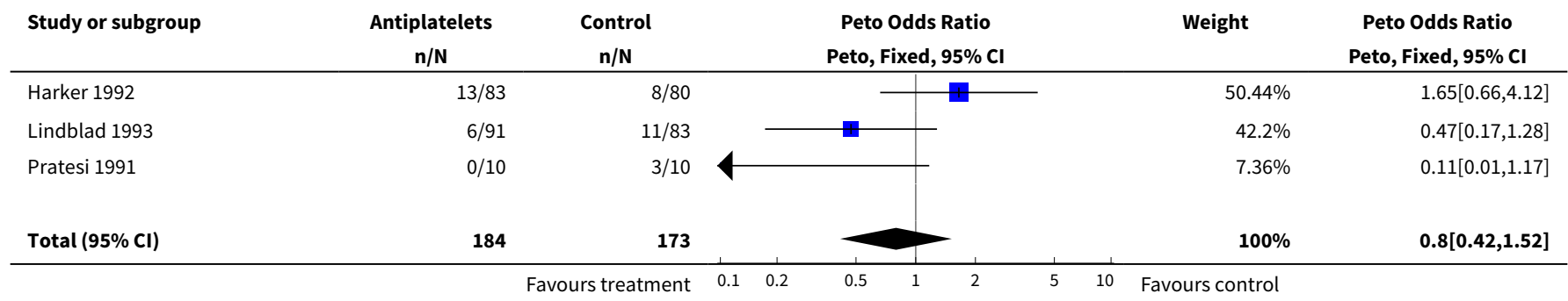




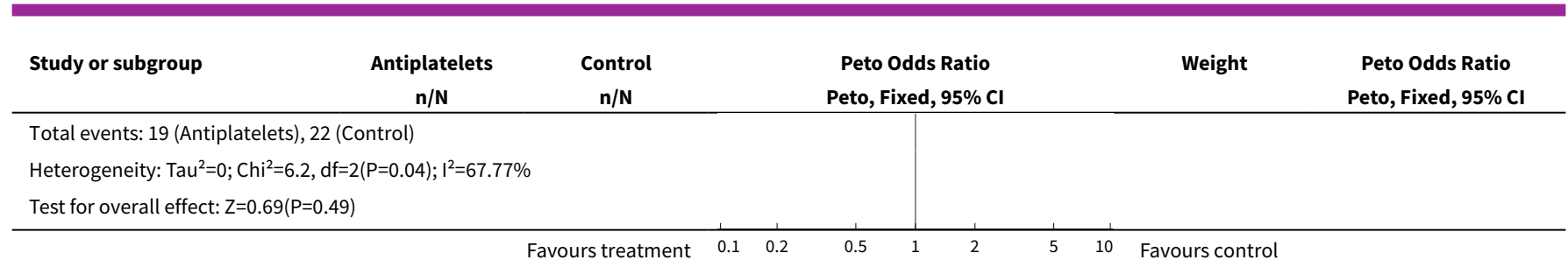

\section{Analysis 1.15. Comparison 1 Antiplatelets versus control, Outcome 15 TIA or amaurosis fugax.}

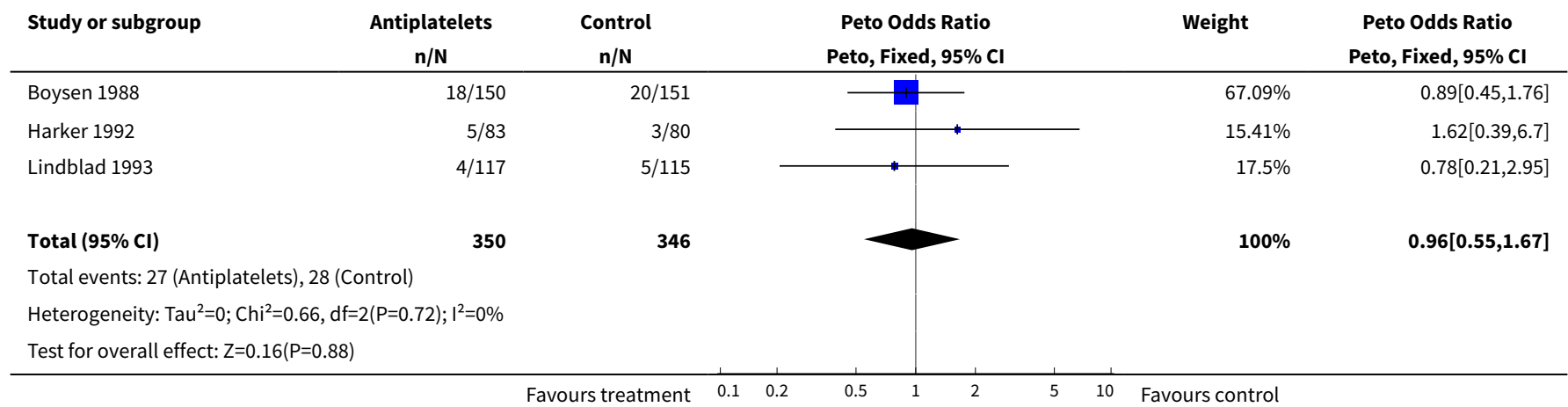

WHAT'S NEW

\begin{tabular}{lll}
\hline Date & Event & Description \\
\hline 23 June 2008 & Amended & Converted to new review format. \\
\hline
\end{tabular}

\section{CONTRIBUTIONS OFAUTHORS}

Ph Lyrer: developing the protocol; fund raising; outcome measures; extraction; data analyses; editing the review.

St Engelter: literature search; outcome measures; extraction; data analyses; raising up the database; contacting authors of studies; drafting and editing the manuscript.

\section{DECLARATIONS OF INTEREST}

None known.

\section{SOURCES OF SUPPORT}

\section{Internal sources}

- Scientific fund of the stroke programme (FO105201), Neurology Dept., University Hospital, Basel, Switzerland.

\section{External sources}

- Freiwillige Akademische Gesellschaft (FAG), Basel, Switzerland.

\section{DIFFERENCES BETWEEN PROTOCOL AND REVIEW}

Differences between this review and the original protocol are as follows.

(1) Addition of two further outcomes: 'non-fatal myocardial infarction' and 'serious vascular events' were added to the review as secondary outcomes. 
(2) Primary outcomes were reduced to two. 'Recurrent stroke' was removed.

(3) An additional secondary endpoint measure 'serious vascular events' was added.

(4) 'Disability' was rephrased to 'death or dependency', as this term is more accurate.

(5) 'Intracerebral haemorrhage' was rephrased to 'intracranial haemorrhage' and moved to secondary outcomes.

(6) The composite outcome event 'stroke and vascular death' was corrected to 'stroke or vascular death'.

(7) One study had a control group that did not receive placebo treatment; instead no treatment was given. It was included in the review.

(8) The title was changed from 'Antiplatelet therapy for preventing stroke after carotid endarterectomy' to 'Antiplatelet therapy for preventing stroke and other vascular events after carotid endarterectomy' in order to take into account that, apart from stroke, several other outcome events were analysed.

\section{N DEX TERMS}

\section{Medical Subject Headings (MeSH)}

^Endarterectomy, Carotid; Amaurosis Fugax [prevention \& control]; Brain Ischemia [prevention \& control]; Carotid Artery, Internal; Carotid Stenosis [* ${ }^{*}$ surgery]; Myocardial Infarction [prevention \& control]; Platelet Aggregation Inhibitors [ ${ }^{\star}$ therapeutic use]; Randomized Controlled Trials as Topic; Stroke [*prevention \& control]

\section{MeSH check words}

Humans 